Supplement of Atmos. Chem. Phys., 14, 7941-7951, 2014

http://www.atmos-chem-phys.net/14/7941/2014/

doi:10.5194/acp-14-7941-2014-supplement

(C) Author(s) 2014. CC Attribution 3.0 License.

(c) (i)

Atmospheric

Chemistry

and Physics

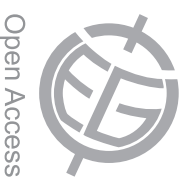

Supplement of

\title{
Production and growth of new particles during two cruise campaigns in
} the marginal seas of China

\section{H. Liu et al.}

Correspondence to: X. H. Yao (xhyao@ouc.edu.cn) and M. Zheng (mzheng@pku.edu.cn) 


\section{Support figures}

2 Figure S1 Particle size distribution in marine atmosphere. (a:16 October to 5 3 November 2011, b:2 to 11 November 2012).

4 Figure S2 Comparison of median diameter of particle mode $\left(\mathrm{D}_{p g, 1}\right)$ and number 5 concentrations of nucleation mode particles $\left(\mathrm{N}_{<30 \mathrm{~nm}}\right)$ between two sites on 4 6 November 2012.

7 Figure S3 New particle formation on 18 October 2011 deducted of the ship plumes.

8 Figure $\mathbf{S 4}$ Variations of median diameter of preexisting particle mode $\left(\mathrm{D}_{p g, 2}\right)$ and 9 number concentrations of median diameter particles $\left(\mathrm{N}_{i}\right)$ of particle growth event over 10 China Seas on 26 October, 2011.

11 Figure $\mathrm{S5}$ Variations of $\mathrm{PM}_{0.1} \mathrm{NH}_{4}{ }^{+}, \mathrm{NO}_{3}{ }^{-}$and $\mathrm{SO}_{4}{ }^{2-}$ concentrations during 5 new 12 particle formation events.

13 Figure S6 MODIS derived chlorophyll a oceanic concentrations on 26 October 2011 over China Seas (pentacle represents the location of new particle burst event).

15 Figure S7 Variations of semi-volatility and non-volatility SOA concentrations during 165 new particle formation events.

17 Figure S8 Schematic of CMAQv4.7 SOA module.

Table S1 Acronym and definition of each SOA species in CMAQ 4.7.1 
(a)

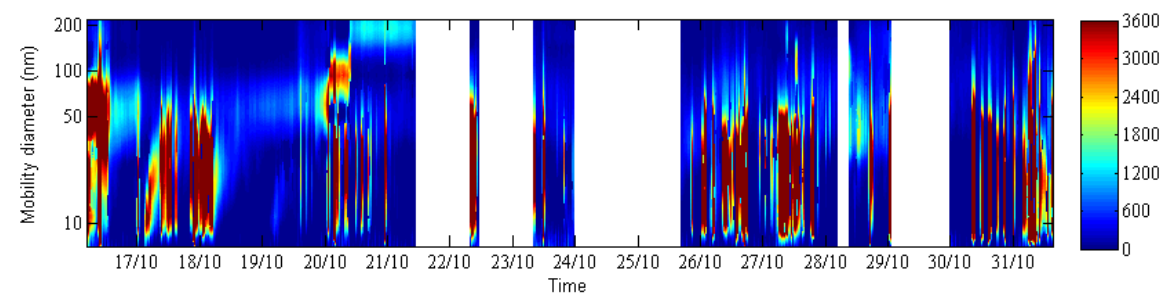

(b)

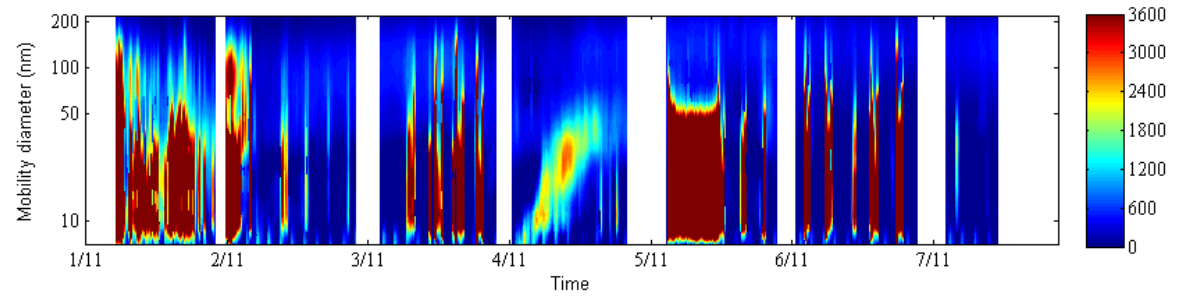

22 Figure S1 Particle size distribution in marine atmosphere. (a:16 October to 5 23 November 2011, b:2 to 11 November 2012).
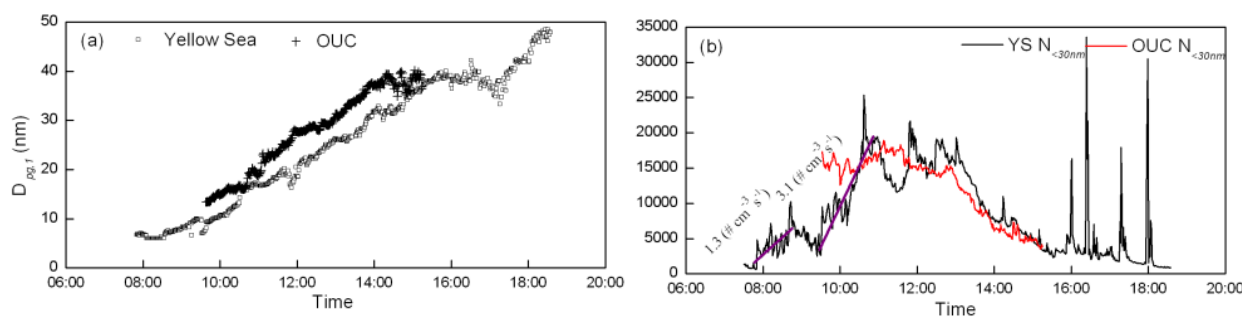

Figure S2 Comparison of median diameter of particle mode $\left(\mathrm{D}_{p g, 1}\right)$ and number concentrations of nucleation mode particles $\left(\mathrm{N}_{<30 \mathrm{~nm}}\right)$ between two sites on 4 November 2012.
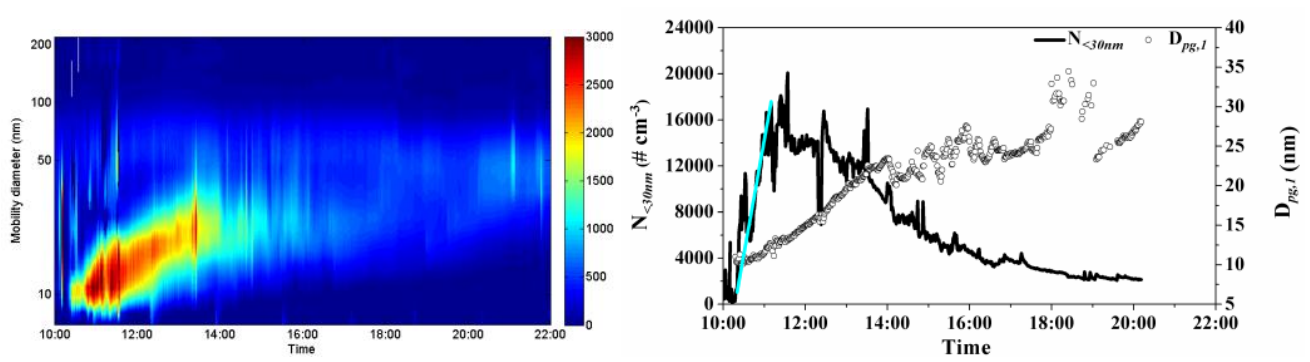

Figure S3 New particle formation on 18 October 2011 deducted of the ship plumes. 


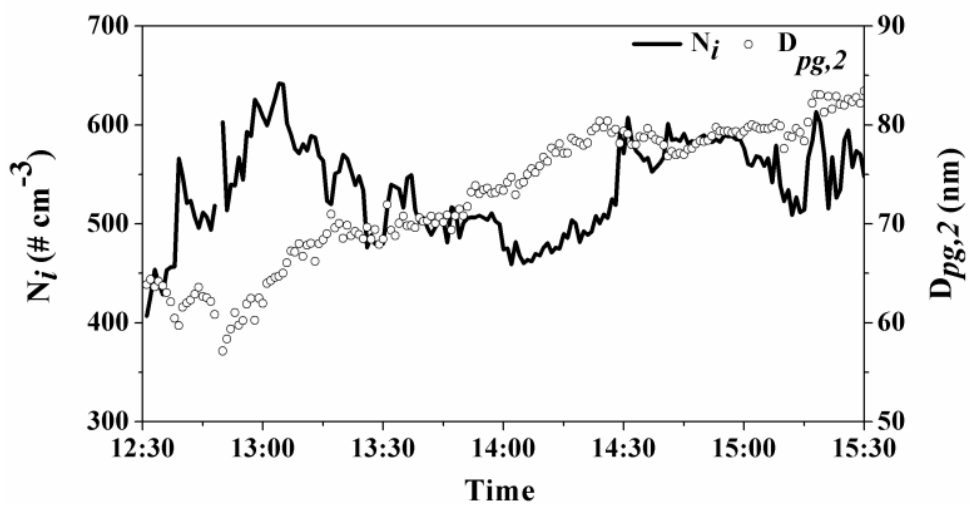

Figure S4 Variations of median diameter of preexisting particle mode $\left(\mathrm{D}_{p g, 2}\right)$ and number concentrations of median diameter particles $\left(\mathrm{N}_{i}\right)$ of particle growth event over China Seas on 26 October 2011.
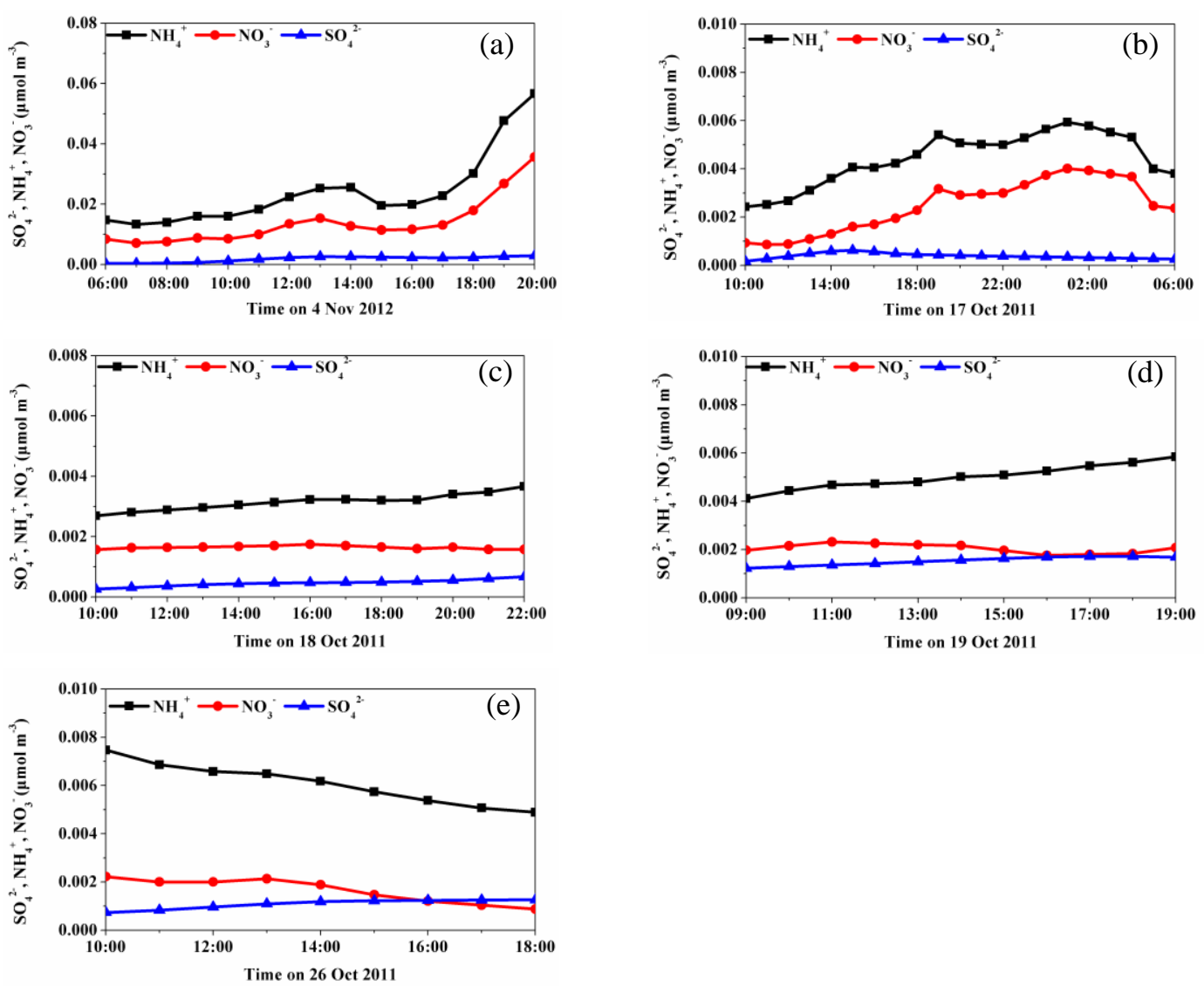

Figure S5 Variations of $\mathrm{PM}_{0.1} \mathrm{NH}_{4}{ }^{+}, \mathrm{NO}_{3}{ }^{-}$and $\mathrm{SO}_{4}{ }^{2-}$ concentrations during 5 new particle formation events (Due to the lack of evaluation about the simulated $\mathrm{PM}_{0.1}$ species with observations and SOA only distributed in $\mathrm{PM}_{0.1-2.5}$ in modeling results, we chose $\mathrm{PM}_{2.5} \mathrm{NH}_{4}{ }^{+}, \mathrm{NO}_{3}{ }^{-}$and $\mathrm{SO}_{4}{ }^{2-}$ in the text but not $\mathrm{PM}_{0.1} \mathrm{NH}_{4}{ }^{+}, \mathrm{NO}_{3}{ }^{-}$and $\mathrm{SO}_{4}{ }^{2-}$. However, simulated species in $\mathrm{PM}_{0.1}$ could also support our analysis). 

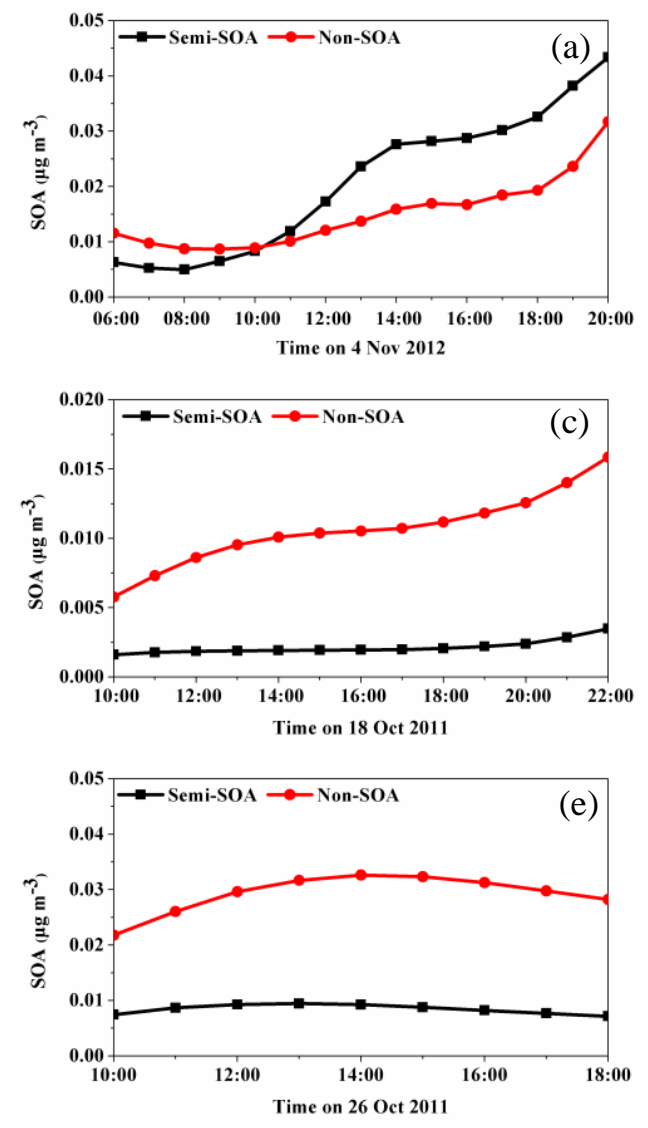


Figure S6 MODIS derived chlorophyll a oceanic concentrations on 26 October 2011 over China Seas (pentacle represents the location of new particle burst event).

Figure S7 Variations of semi-volatile and non-volatile SOA concentrations during 5 new particle formation events (Non-SOA includes ABNZ3, ATOL3, AXYL3, AOLGA, AISO3, AOLGB and AORGC, while Semi-SOA includes AALK,ABNZ1, ABNZ2, ATOL1, ATOL2, AXYL1, AXYL2, AISO1, AISO2, ATRP1, ATRP2 and ASQT. Due to the temperature-related characteristics, SOA volatility always varies with different conditions, therefore we chose total SOA concentrations in the text, however, different volatility SOA could also support our analysis). 


\section{Supporting information}

\section{SOA simulation in CMAQ}

The U.S. EPA Community Multi-scale Air Quality Model (CMAQ v4.7.1; Byun and Ching, 1999) with the AE5 SOA module was used to simulate the processes of secondary organic aerosol formation during new particle burst events.

Related SOA formation reactions and SOA composition in CMAQ4.7.1 are shown in Figure S8 (Carlton et al., 2010). Table S1 provides the acronym and definition of each SOA species. The concentration of SOA in this study represents the sum of 19 species listed in Table S1. Four types (7 species) of were non-volatile SOA (Fig. S7 and S8), while other SOA species was treated as semi-volatile (Carlton et al., 2010).

Table S1 Acronym and definition of each SOA species in CMAQ 4.7.1.

\begin{tabular}{|c|l|}
\hline Acronym & \multicolumn{1}{|c|}{ Definition } \\
\hline AALK & Semi-volatile SOA from alkanes \\
\hline ABNZ1,ABNZ2 & Semi-volatile SOA from benzene \\
\hline ABNZ3 & Non-volatile SOA from benzene (low-NO ${ }_{\mathrm{x}}$ ) \\
\hline ATOL1,ATOL2 & Semi-volatile SOA from high-yield aromatics \\
\hline ATOL3 & Non-volatile SOA from high-yield aromatics (low-NO $\left.{ }_{\mathrm{x}}\right)$ \\
\hline AXYL1,AXYL2 & Semi-volatile SOA from low-yield aromatics \\
\hline AXYL3 & Non-volatile SOA from low-yield aromatics (low-NO ${ }_{\mathrm{x}}$ ) \\
\hline AOLGA & Oligomers from anthropogenic SOA precursors \\
\hline AISO1,AISO2 & Semi-volatile SOA from isoprene \\
\hline AISO3 & Acid-enhanced SOA from isoprene \\
\hline ATRP1, ATRP2 & Semi-volatile SOA from monoterpenes \\
\hline ASQT & Semi-volatile SOA from sesquiterpenes \\
\hline AOLGB & Oligomers from biogenic SOA precursors \\
\hline AORGC & Non-volatile from aqueous-phase oxidation of glyoxal and methylglyoxal \\
\hline
\end{tabular}




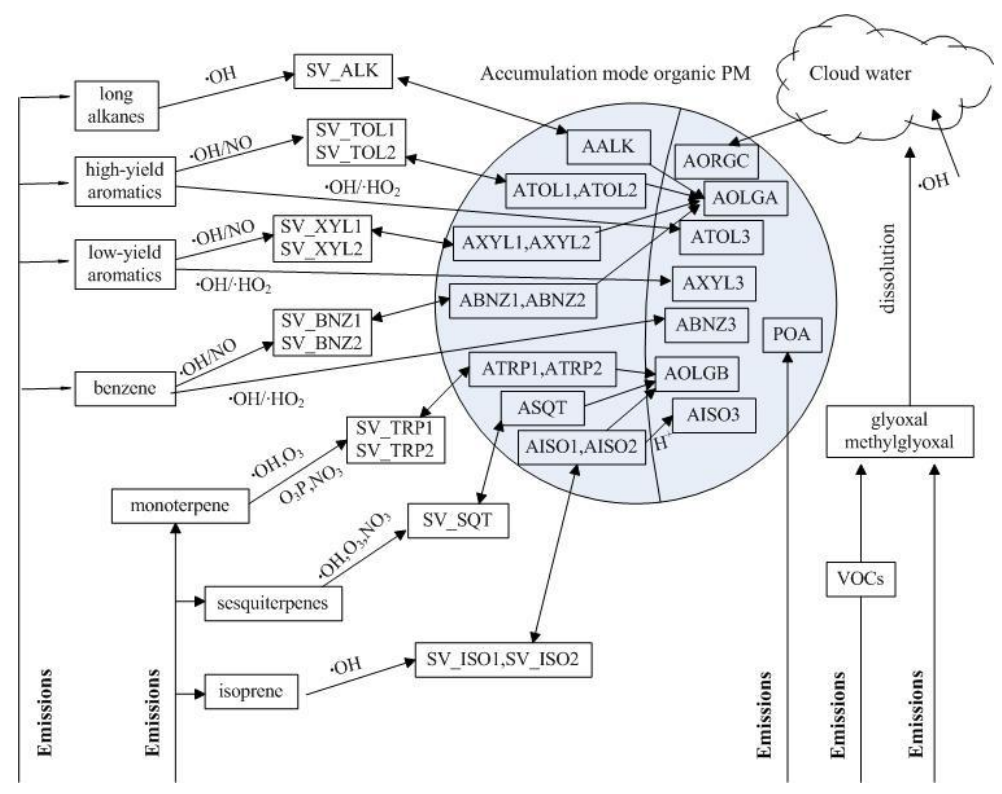

Figure S8 Schematic of CMAQv4.7 SOA module (Carlton et al., 2010)

\section{An approach used to deduct the contribution of ship-emitted primary particles}

The ship-emitted primary particles exhibited a uni-modal size distribution of their number concentrations in our two cruise campaign. The mode was distributed at 25-29 $\mathrm{nm}$. However, there was a small difference between these number concentration size distribution spectra, depending on the concentration. Thus, the measurements in low background number concentration days were used to establish a library of number concentration size distribution spectra of ship-emitted particles in various concentration levels.

In the cruise campaign, the observed concentration some times reflects a combination of the contributions from new particle formation, ship-emitted particles and background particles. To deduct the contribution from ship emissions, the number concentration size distribution spectrum of ship-emitted particles with the concentration at 25-29 $\mathrm{nm}$ same as the observed particles at the size were selected. The observed number concentrations minus the values in the selected size distribution spectrum generated the concentrations of particles from new particle formation and background particles.

\section{References:}

Carlton, A.G., Bhave, P.V., Napelenok, S.L., Edney, E.O., Sarwar, G., Pinder, R.W., Pouliot, G.A. and Houyoux, M.: Model representation of secondary organic aerosol in CMAQ v4.7, Environ. Sci. Technol., 24, 8553-8560, 2010.

Byun, D., Ching, J.: Science Algorithms of the EPA Models-3 Community Multiscale Air Quality (CMAQ) Modeling System, EPA Report 600/R-99/030, Washington DC, 1999, http://www.epa.gov/asmdnerl/models3/doc/science/science.html. 